\title{
EDITORIAL
}

\section{Schizophrenia and COVID-19: risks and recommendations}

\author{
Lais Fonseca, ${ }^{1,2 *}$ Elton Diniz, ${ }^{1,2 *}$ Guilherme Mendonça, ${ }^{3}$ Fernando Malinowski, ${ }^{1,2}$ Jair Mari, ${ }^{3,4}$ \\ Ary Gadelha ${ }^{1,2,4}$ iD \\ ${ }^{1}$ Laboratório Interdisciplinar de Neurociências Clínicas (LiNC), Universidade Federal de São Paulo (UNIFESP), São Paulo, SP, Brazil. \\ ${ }^{2}$ Programa de Esquizofrenia (PROESQ), Departamento de Psiquiatria, UNIFESP, São Paulo, SP, Brazil. ${ }^{3}$ Departamento de Psiquiatria, \\ UNIFESP, São Paulo, SP, Brazil. ${ }^{4}$ Centro de Pesquisa e Inovação em Prevenção de Transtornos Mentais e Uso de Álcool e Outras Drogas \\ (CEPIPREV), UNIFESP, São Paulo, SP, Brazil. * These authors have contributed equally to this manuscript.
}

"Is my son at risk in view of COVID-19?" A patient's mother contacted our Schizophrenia Outpatient Clinic as soon as news about the coronavirus pandemic reached Brazilian headlines. I immediately remembered how we hear in mental health services that "patients with severe mental illness are immune deficient." But is this true? What are the implications of the COVID-19 pandemic for schizophrenia patients and their families?

Coronavirus disease (COVID-19), caused by severe acute respiratory syndrome coronavirus 2 (SARS-CoV-2), has affected over 750,000 people worldwide and has led to 36,405 deaths, ${ }^{1}$ becoming a major concern for all health systems. Although the global prevalence of schizophrenia is $\cong 0.4 \%,{ }^{2}$ it represents a large burden to families and society. These patients also have high mortality rates and comorbid medical conditions. If they are more susceptible to SARS-CoV2 infection, have worse clinical outcomes once contaminated, or have psychotic relapses in the context of the COVID-19 pandemic, there will be an additional burden to a system that is already pressed to the limit. To help families and policy makers make better informed decisions and develop preventive measures, we intend to address the following questions: Are schizophrenia patients at higher risk of: 1) being contaminated; 2) mortality; and 3) suffering a psychotic relapse?

Regarding the first question, we performed a literature review through Medline, searching from inception to March 16, 2020. We included original, peer-reviewed articles in English assessing any diagnosis of respiratory infection, regardless of causal agent, among schizophrenia patients. All 315 reports were screened blindly by two authors in two phases (title and abstract; and full-text review), resulting in 18 articles selected for data retrieval.

Few reports specifically addressed viral infections. Overall, the articles suggested higher odds of pneumonia and mortality. Although community-acquired pneumonia is nontransmissible, it could indicate immunodeficiency. ${ }^{3,4}$ Thus, our search indicated that this population could be at higher risk of developing respiratory infections, especially when

Correspondence: Ary Gadelha, Laboratório Interdisciplinar de Neurociências Clínicas (LiNC), Departamento de Psiquiatria, Universidade Federal de São Paulo (UNIFESP), Rua Pedro de Toledo, 669, $3^{\circ}$ andar, CEP 05039-032, São Paulo, SP, Brazil.

E-mail: aryararipe @gmail.com

Submitted Mar 24 2020, accepted Mar 25 2020, Epub Apr 092020. comorbid medical conditions and lifestyle risk factors are involved.

Older age and clinical comorbidities increase mortality rates among COVID-19 patients. ${ }^{5}$ More than $70 \%$ of all schizophrenia patients also have one or more clinical conditions, ${ }^{6}$ including diabetes type $11,{ }^{7,8}$ pulmonary chronic disease, ${ }^{9}$ and hypertension/coronary heart disease. ${ }^{10,11}$ Smoking estimates among schizophrenia patients vary from 50 to $90 \%{ }^{12}$ compared to $20-30 \%$ in the general population, and involve higher smoking intensity, another potential risk factor for respiratory complications, ${ }^{13}$ although it is not yet clear whether COVID-19 outcomes are worse among smokers. ${ }^{14}$ Spirometric assessment indicates that schizophrenia patients have impaired lung function, and they are more often diagnosed with restrictive and obstructive pulmonary diseases. ${ }^{15}$ In addition, when hospitalized for pulmonary conditions, schizophrenia patients have higher rates of intensive care unit admissions, acute respiratory failure, mechanical ventilation, and in-hospital death than other patients. ${ }^{16}$ They also have a higher risk of acute organ dysfunction than the general population when admitted to the intensive care unit, regardless of cause. ${ }^{16}$ Overall, most schizophrenia patients would fit at least one known risk group for COVID-19 and, if admitted to a hospital, should be considered at increased risk of worse clinical outcomes.

Although this review did not yield a definite answer to our questions, the contextual data lead us to infer that there is a greater infection risk in schizophrenia patients. Quarantine has been proven necessary when a site reaches a certain level of COVID-19 contamination, and it has been decisive in positive outcomes, especially when implemented early. ${ }^{17}$ Due to its transmission characteristics, COVID-19 requires both respiratory and contact isolation. ${ }^{18}$ Schizophrenia patients appear to have greater difficulty following adequate hygiene practices than the general population. ${ }^{19}$ Oral hygiene deficits have been particularly well documented ${ }^{20}$ and could certainly increase vulnerability to respiratory diseases. ${ }^{21}$ Schizophrenia inpatients

How to cite this article: Fonseca L, Diniz E, Mendonça G, Malinowski F, Mari J, Gadelha A. Schizophrenia and COVID-19: risks and recommendations. Braz J Psychiatry. 2020;42:236-238. http://dx.doi.org/10.1590/1516-4446-2020-0010 
Table 1 Recommendations for health professionals and families regarding schizophrenia patients

1. Schizophrenia patients should follow the same health instructions (e.g., influenza vaccine - unless specific restrictions apply) and receive the same treatment as clinical high-risk groups for COVID-19.

2. General practitioners treating COVID-19 patients should pay special attention to those with schizophrenia, since they could minimize or have difficulty describing respiratory symptoms.

3. Mental health professionals should remotely monitor unstable outpatients and, when possible, use telehealth (internet-based) technologies to provide more frequent clinical contact and support for emerging concerns.

4. Mental health services should inform patients and families of all procedures to be followed during this period and should provide clear remote contact channels to minimize overcrowding and exposure. However, families should monitor for signs of relapse and contact mental health services as soon as possible.

5. Professionals and families should promote and monitor adherence to antipsychotic medication regimens, as well as ensure access to prescriptions, perhaps organizing a delivery system. It should also be emphasized that patients should continue regular medication regimens, including clozapine.

6. To reduce emotional distress - and possibly psychotic relapse - families and patients should be advised to:

- Anticipate stress reactions and be informed about them by professionals.

- Prepare for quarantine, which can be better adhered to if patients and families receive more information about the disease, about the benefits of quarantine (both personally and in terms of public health), and about quarantine procedures (such as adequate supplies of food and medication). ${ }^{26}$

- Limit media exposure, since overexposure to broadcasts of stressful situations has been linked to negative mental health outcomes, ${ }^{27}$ and avoid misinformation.

- In as much as possible, develop new routines that include leisure activities and physical exercise.

are at additional risk due enclosed treatment environments. Consequently, impaired judgement and poor selfcare, two features commonly observed in schizophrenia, could hinder compliance with health recommendations and put patients, their families, and health professionals at risk.

Lower access to adequate medical care ${ }^{22}$ - one possible explanation for increased mortality in schizophrenia could also aggravate this scenario. Patients and their families may have more difficulty identifying the initial symptoms of COVID-19 and seek health services. In addition, even if they do request medical assistance, there is a higher chance they will not receive proper assessment or treatment due to the stigma surrounding schizophrenia. ${ }^{23}$

However, beyond the direct risk of infection, could COVID-19 indirectly lead to relapse among schizophrenia patients? The main collective sanitary strategy for preventing contamination is social isolation, which could generate considerable distress, both for patients and caregivers. ${ }^{24,25}$ As a result, lack of access to regular psychosocial interventions or medication (and subsequent reduced adherence) could, of course, increase the chances of psychotic symptoms, which is a major concern. Nonetheless, we believe that exposure to such a stressful life event, changes of routine, and interpersonal anxiety due to prolonged quarantine or even the fear of contracting the disease could also act as important triggers.

To the best of our knowledge, no study has provided details on COVID-19 prevalence or outcomes in schizophrenia patients. However, we believe that the available evidence suggests they:

1) May have more difficulty following quarantine and "respiratory etiquette" procedures and, thus, are at higher risk of contamination;
2) Are at higher risk of poor COVID-19 outcomes, mainly due to higher comorbidity rates and a possible immunodeficiency associated with schizophrenia;

3) Are at higher risk of relapse, considering the emotional distress added to an already vulnerable group during an infectious disease outbreak, their limited access to community care, and the risk of interrupting medication.

Such risks vary from patient to patient according to clinical comorbidities, cognitive impairment, acute symptoms, and family support, which can influence disease severity and general health conditions.

Thus, we have produced a list of suggestions (Table 1) that combine current recommendations for COVID-19 prevention (https://www.who.int/emergencies/diseases/novelcoronavirus-2019/technical-guidance) and the particulari ties of schizophrenia.

In conclusion, schizophrenia patients are at higher risk of infection and worse outcomes, especially if affected by clinical comorbidities. They are also vulnerable to worsening psychiatric symptoms and relapse due to fear of the disease, stress, and the boredom associated with compulsory isolation. Therefore, health professionals and families should provide extra attention and support to prevent COVID-19 infection among individuals with schizophrenia and should detect both respiratory and psychiatric symptoms as early as possible.

\section{Acknowledgements}

This study was financed in part by the Coordenação de Aperfeiçoamento Pessoal de Nível Superior (CAPES; Finance Code 001).

The authors would like to thank Sarah Nicolelli, founder of the Associação Mãos de Mães de Pacientes com 
Esquizofrenia (AMME). Her question reminded us that psychiatry and science are performed by people to help people. We would also like to thank the Associação Brasileira de Familiares, Amigos e Portadores de Esquizofrenia (ABRE), who always support the Programa de Esquizofrenia (PROESQ) team and our patients.

\section{Disclosure}

AG has been a consultant and/or advisor to or has received honoraria from Aché, Daiichi-Sankyo, Torrent, Cristalia, and Janssen. The other authors report no conflicts of interest.

\section{References}

1 World Health Organization (WHO). Coronavirus disease (COVID-19) situation reports [Internet]. 2020 [cited 2020 Mar 31]. www.who.int/ emergencies/diseases/novel-coronavirus-2019/situation-reports

2 Saha S, Chant D, Welham J, McGrath J. A systematic review of the prevalence of schizophrenia. PLoS Med. 2005;2:e141.

3 Vadamalai K, Sanchez-Tejera D, Bress J, Mustafa SS. screening for humoral immunodeficiency in patients with community-acquired pneumonia. J Hosp Med. 2019;14:33037.

4 Ekdahl K, Braconier JH, Svanborg C. Immunoglobulin deficiencies and impaired immune response to polysaccharide antigens in adult patients with recurrent community-acquired pneumonia. Scand $\mathrm{J}$ Infect Dis. 1997;29:401-7.

5 Zhou F, Yu T, Du R, Fan G, Liu Y, Liu Z, et al. Clinical course and risk factors for mortality of adult inpatients with COVID-19 in Wuhan, China: a retrospective cohort study. Lancet. 2020;395: 1054-62.

6 Carney CP, Jones L, Woolson RF. Medical comorbidity in women and men with schizophrenia: a population-based controlled study. J Gen Intern Med. 2006;21:1133-7.

7 Subramaniam M, Chong SA, Pek E. Diabetes mellitus and impaired glucose tolerance in patients with schizophrenia. Can J Psychiatry. 2003;48:345-7.

8 Suvisaari J, Mantere O, Keinanen J, Mantyla T, Rikandi E, Lindgren $\mathrm{M}$, et al. Is it possible to predict the future in first-episode psychosis? Front Psychiatry. 2018;9:580.

9 Zareifopoulos N, Bellou A, Spiropoulou A, Spiropoulos K. Prevalence of comorbid chronic obstructive pulmonary disease in individuals suffering from schizophrenia and bipolar disorder: a systematic review. COPD. 2018;15:612-20.

10 Olfson M, Gerhard T, Huang C, Crystal S, Stroup TS. Premature mortality among adults with schizophrenia in the United States. JAMA Psychiatry. 2015;72:1172-81.

11 Sugai T, Suzuki Y, Yamazaki M, Shimoda K, Mori T, Ozeki Y, et al. High prevalence of obesity, hypertension, hyperlipidemia, and diabetes mellitus in Japanese outpatients with schizophrenia: a nationwide survey. PLoS One. 2016;11:e0166429.

12 Hartz SM, Pato CN, Medeiros H, Cavazos-Rehg P, Sobell JL, Knowles JA, et al. Comorbidity of severe psychotic disorders with measures of substance use. JAMA Psychiatry. 2014;71:248-54.

13 Haga T, Ito K, Sakashita K, Iguchi M, Ono M, Tatsumi K. Risk factors for pneumonia in patients with schizophrenia. Neuropsychopharmacol Rep. 2018;38:204-9.

$14 \mathrm{Cai} \mathrm{H}$. Sex difference and smoking predisposition in patients with COVID-19. Lancet Respir Med. 2020;8:e20.

15 Partti K, Vasankari T, Kanervisto M, Perälä J, Saarni SI, Jousilahti P, et al. Lung function and respiratory diseases in people with psychosis: population-based study. Br J Psychiatry. 2015;207:37-45.

16 Shen HN, Lu CL, Yang HH. Increased risks of acute organ dysfunction and mortality in intensive care unit patients with schizophrenia: a nationwide population-based study. Psychosom Med. 2011;73:620-6.

17 Tang B, Xia F, Tang S, Bragazzi NL, Li Q, Sun X, et al. The effectiveness of quarantine and isolation determine the trend of the COVID-19 epidemics in the final phase of the current outbreak in China. Int J Infect Dis. 2020 Mar 11. pii: S1201-9712(20)30137-5. doi: http://10.1016/j.ijid.2020.03.018. [Epub ahead of print]

$18 \mathrm{Wu}$ Z, McGoogan JM. Characteristics of and important lessons from the coronavirus disease 2019 (COVID-19) outbreak in China: summary of a report of 72314 cases from the Chinese center for disease control and prevention. JAMA. 2020 Feb 24. doi: http://10.1001/ jama.2020.2648. [Epub ahead of print]

19 Van Haaster I, Lesage AD, Cyr M, Toupin J. Problems and needs for care of patients suffering from severe mental illness. Soc Psychiatry Psychiatr Epidemiol. 1994;29:141-8.

20 Yang M, Chen P, He MX, Lu M, Wang HM, Soares JC, et al. Poor oral health in patients with schizophrenia: a systematic review and metaanalysis. Schizophr Res. 2018;201:3-9.

21 Azarpazhooh A, Leake JL. Systematic review of the association between respiratory diseases and oral health. J Periodontol. 2006; 77:1465-82.

22 Bradford DW, Kim MM, Braxton LE, Marx CE, Butterfield M, Elbogen EB. Access to medical care among persons with psychotic and major affective disorders. Psychiatr Serv. 2008;59:847-52.

23 Lawrence $D$, Kisely $S$. Inequalities in healthcare provision for people with severe mental illness. J Psychopharmacol. 2010;24(4 Suppl):61-8.

24 Trémeau F, Antonius D, Malaspina D, Goff DC, Javitt DC. Loneliness in schizophrenia and its possible correlates. An exploratory study. Psychiatry Res. 2016;246:211-7.

25 Hayes L, Hawthorne G, Farhall J, O'Hanlon B, Harvey C. Quality of life and social isolation among caregivers of adults with schizophrenia: policy and outcomes. Community Ment Health J. 2015;51:591-7.

26 Webster R, Brooks S, Smith L, Woodland L, Wessely S, Rubin J. How to improve adherence with quarantine: rapid review of the evidence [Internet]. medRxiv. 2020 Jan 1 [cited 2020 Mar 26]. https:// doi.org/10.1101/2020.03.17.20037408

27 Pfefferbaum B, Newman E, Nelson SD, Nitiéma P, Pfefferbaum RL, Rahman A. Disaster media coverage and psychological outcomes: descriptive findings in the extant research. Curr Psychiatry Rep. 2014;16:464. 